\title{
(RE)LEMBRANDO ELVIRA DE FELICE: GESTOS E FALAS DE ENFERMEIRAS SOBRE O BANHO NO LEITO, UMA TÉCNICA/TECNOLOGIA DE ENFERMAGEM
}

\author{
Remembering Elvira de Felice: \\ Gestures and speechs of the nurses about the bathing in the bed, \\ a technique/ technology of Nursing \\ Reacordando Elvira de Felice: \\ Gestos y hablas de enfermeras sobre el baño en el lecho, \\ una técnica/ tecnología de Enfermería
}

Nébia Maria Almeida de Figueiredo

Vilma de Carvalho

Maria Antonieta Rubio Tyrrell

\begin{abstract}
Resumo
Trata-se de uma pesquisa quanti-qualitativa sobre banho no leito, com os objetivos de identificar expressões verbais e caracterizar expressões não verbais durante a execução da atividade de banhar e de ser banhada.. A coleta de dados incluiu o registro de falas, gestos e expressões durante a Cena de Reflexão, uma dramatização do banho em sala de aula, com a participação de 32 enfermeiras e alunas de pós-graduação - mestrado. Os resultados indicaram dois núcleos de representações: o primeiro, "0 Corpo que Toca e Fala"; e o segundo, "0 Corpo que Toca e Cala". A Multireferencialidade, Subjetividade, Psicossociologia e as concepções de Nightingale, Figueiredo e Carvalho foram usadas como apoio teórico. Os resultados constataram dificuldades das enfermeiras em relação ao toque e ao corpo nu, durante o procedimento técnico, e também quando opinavam e defendiam, de fato, o próprio corpo e o toque como intermediadores de emoções, subjetividade, estética, sexualidade e sensualidade
\end{abstract}

Palavras-chave: Enfermagem. Higiene da pele. Tato. Tecnologia.

\begin{abstract}
This is about a quantitative and qualitative research about the bath in the bed, with the objectives to identify verbal expressions and to characterize not verbal expressions during the execution of the activity to bathe and of being bathed. The collection of data included the register of speechs, gestures and expressions during the Scene of Reflection, a dramatization of the bath in classroom, with the participation of 32 nurses and students of Postgraduation - masters. The results had indicated two nuclei of representations: the first one, "the Body that Touchs and Speaks"; and the second one, "the Body that Touchs and Quiet". The Multireferentiality, Subjectivity, Psychosociology and the conceptions of Nightingale, Figueiredo and Carvalho had been used as theoretical support. The results had evidenced difficulties of the nurses in relation to the touch and to the naked body, during the technician procedure, and also when they thought and they defended, in fact, the proper body and the touch as intermediate of emotions, subjectivity, aesthetic, sexuality and sensuality.
\end{abstract}

\section{Resumen}

Se trata de una investigación cuanti-cualitativa sobre el baño en el lecho, con los objetivos de identificar expresiones verbales y caracterizar expresiones no verbales durante la actividad de bañar y de ser bañada. La recolección de datos incluyó el registro de hablas, gestos y expresiones durante la Escena de Reflexión, una dramatización del baño en clase, con la participación de 32 enfermeras ya alumnas de posgrado (Maestría). Los resultados indicaron dos núcleos de representaciones: "El cuerpo que toca y habla" y "El cuerpo que toca y calla". La Multireferencialidad, Subjetividad, Psicosociología y las concepciones de Nightgale, Figueiredo Y Carvalho fueron usadas como soporte teórico. Se constató dificultades de las enfermeras en relación al toque y al cuerpo desnudo en el decurso del procedimento técnico, y también cuando opinaban y defendían, en realidad, el propio cuerpo y el toque como intermediadores de emociones, subjetividad, estética, sexualidad y sensualidad.

Palabras clave:

Enfermería. Cuidados de la Piel. Tacto. Tecnología
Keywords:

Nursing. Skin care. Touch. Technology. 


\section{O QUE APRENDEMOS COM ELVIRA DE FELICE}

No Rio de Janeiro, seguindo-se pela Avenida Presidente Vargas, no sentido Praça Onze - Cidade Nova (Centro), encontra-se à direita o Hospital Escola São Francisco de Assis (HESFA), o "Velho Chico", carinhosamente assim chamado pelas enfermeiras, principalmente as "Anna Nery", que aprenderam a praticar, nas suas várias enfermarias, a Arte de Enfermagem.

Na Rua Afonso Cavalcante 275, atrás do HESFA, situase o Pavilhão de Aulas da Escola de Enfermagem Anna Nery (EEAN/UFRJ), - o P.A., prédio conhecido das enfermeiras, gracioso e resistente ao tempo, cuja paisagem circundante, - desde sua fundação no final dos anos 20 (pedra fundamental em 1926), já mudou significativamente. Sua "cor de rosa" destaca-o dos demais prédios - a cor da vida, a cor do movimento, a cor da emoção que atravessa e transcende os vários momentos de "ensinar e aprender enfermagem".

No P.A., mais mulheres do que homens aprenderam 0 valor de viver, o valor da vida. Nesse "espaço cor de rosa", a De Felice, como é designada por nós a Professora Doutora Elvira De Felice Souza, dedicou todo o seu magistério, instalando nele o seu "comando maior" para ensinar o básico da profissão - a Enfermagem Fundamental - Fundamentos, Ciência e Arte de Enfermagem (e outras disciplinas conexas).

0 espaço de ensinar a e aprender enfermagem encontrava-se no primeiro andar, à esquerda de quem sobe a escada, e era denominado laboratório de demonstrações e servia aos objetivos de aulas teóricas e práticas e, também, aos treinamentos de técnicas e procedimentos. Atualmente, situa-se ali 0 Departamento de Enfermagem Fundamental (Sala Professora Elvira De Felice Souza). A nosso ver, e para o sentido deste trabalho, o espaço de tal laboratório poderia ser, também, o cenário de Encenação de Iniciação, um espaço facilitador para a aprendizagem da "dança" de movimentos corporais e introjeção de valores e do surgimento de emoções, todos relacionados ao saber e ao treinamento das técnicas de enfermagem.

Era o espaço típico da De Felice, onde ela ensinava a arte de enfermagem. Ali, no estilo de uma réplica, havia mobiliário de metal em disposição e detalhes de enfermaria devidamente arranjada, com quatro unidades, para que tivéssemos a impressão de estarmos no ambiente do cliente - camas arrumadas (lençóis, colcha e travesseiro), cadeiras e mesinhas, armários, escadinhas, biombos - faziam com que nossa imaginação fluísse, levandonos para o mundo hospitalar; tudo preparado segundo requisitos nightingaleanos, com instruções sobre ventilação, limpeza, iluminação, e sem ruídos. Conferia com exigências de uma ecologia de enfermagem para 0 bem-estar compatível com a saúde. Sobre as camas, os manequins assexuados simbolizavam "corpos imóveis", em contraste com um ambiente de constante movimento. Ali mesmo, movimentávamos nossos corpos sensíveis para aprender, em situações artificialmente arquitetadas, como se partícipes das próprias circunstâncias da vida, tão objetivas quanto possível, estimulavam-nos para o que poderia ou deveria ser feito, no e para o corpo "vivomóvel", e para quando estivéssemos prontas para atravessar a rua e, então, poder cuidar dos clientes do HESFA - clientes holísticos: matéria / mente / espírito.

Treinávamos exaustivamente os primeiros passos das técnicas, entendidas como procedimentos de enfermagem sob o olhar carinhoso, discreto e firme da De Felice e, às vezes, de professoras assistentes. Não se falava de humanização das técnicas como hoje, mas aprendíamos que, na execução de uma técnica, deveríamos equilibrar harmonia com as leis da física, regras de condutas e princípios científicos, com habilidade e destreza manual para fazer nosso trabalho com "eficiência, segurança, economia de tempo e de energia" (requisitos da arte de enfermagem). Aprendemos também outras técnicas baseadas nos "princípios teóricos tayloristas" (1), sendo que o principal é que aprendíamos, no laboratório de demonstração, como poderíamos, mais tarde, cuidar de pessoas enfermas, e a ênfase ou ponto comum era que as ações de enfermagem incidiam em tarefasc, baseadas em princípios organizacionais / administrativos, e prestavam-se à empreitada (ou missão na fala da De Felice) de prestar cuidados de enfermagem, com prazo certo e de modo a garantir economia de tempo e produtividade.

Mas isto, ou não era dito de modo muito claro ou nossa compreensão era limitada. Pois, quando De Felice falava de procedimentos, deixava transparecer, principalmente, a sensibilidade e a sensualidade que percebíamos através do movimento de seu corpo. Com certeza, seu jeito de se mostrar, enquanto "demonstrava", era bem diferente de sua fala sobre as técnicas, e a expressão de seu corpo significava, para nós, muito mais do que ela dizia. Naquela ocasião, na EEAN, não se falava de corpo, embora as mulheres, no mundo, já estivessem fazendo sua revolução de liberalismo sexual / sensual - enfrentando seu corpo, sua sexualidade, sua sensualidade. 
A vida das alunas de enfermagem, nas décadas de 60 e 70, período da Ditadura Militar, fluía regularmente e éramos protegidas, resguardadas atrás dos muros do P.A. e da residência denominada Internato, localizada na Avenida Rui Barbosa 762, em Botafogo. De certa forma, vivíamos um tanto alienadas em um mundo de mudanças aceleradas. Pouco nos restava a fazer e, por isso, a atenção era despertada pela curiosidade e sensibilidade através do treino naqueles manequins para aprender uma arte insigne designada - a arte de enfermeira(2). Seguramente (pode-se dizer), não havia a devida interação e nem emoção completa entre alunas e procedimentos, embora se justificasse que "aprender a cuidar nos manequins" era mais seguro para os clientes.

Nossa lembrança serviu de partida para nossas reflexões e impulsionou os motivos para esta pesquisa. Para (re)lembrar De Felice, escolhemos o "banho no leito"d, com base no pressuposto de que é a técnica / tecnologia de cuidar mais completa, apesar de certa complexidadee, para aqueles em início de aprendizagem. Haja vista que, além de abranger conhecimentos diversos, é uma ação específica de enfermagem. Acrescente-se a isso que as alunas precisavam de apoio para 0 desenvolvimento de habilidades psicomotoras e para a aplicação dos princípios de anatomia, fisiologia, microbiologia. E precisavam de conhecimentos de física e mecânica corporal, enquanto se preparavam emocionalmente para dar o banho no leito, atualmente desprestigiado / desvalorizado como atividade do cuidado de enfermagem por ser mais considerado como técnica / procedimento "não científico", que não confere status nem autonomia profissional.

0 que temos observado, mais recentemente, é que enfermeiras(0s) assistenciais e estudantes de enfermagem mostram-se talvez mais encantados com as tecnologias de ponta, representadas por aparelhos e equipamentos sofisticados que realizam medidas biológicas no corpo do cliente, antes verificadas de maneira manual. Esse é um sentimento estranho, às vezes reforçado por grande parte de enfermeiras(os) professores, como uma forma de "poder" e de "saberfazer" coisas mais habituais e rotineiras, que também são do domínio de muitos.

A nosso ver, abrir mão de uma técnica de cuidar tão peculiar de favorecer o conforto, tão específica, e que envolve cuidados diretos - esfera de atuação da enfermeira - é não perceber os requisitos que ela impõe - de científico, de emocional / sensível, de interação sociológica, de transação cultural, e de relacionamento interpessoal. Quando De Felice falava sobre o banho no leito, explicava os requisitos, e mesmo sem referir-se ao corpo, falava do "preparo psicológico" e demonstrava na ação as atividades técnicas da enfermeira e toda a sensibilidade singular de que dispunha e expressava, desde o preparo do material até a culminação do banho.

Destarte, para nós que aprendíamos, De Felice em torno do leito, treinando / demonstrando procedimentos técnicos em manequins, realizava e expressava sua "dança corporal", provocando um misto de encantamento e de perplexidade em suas discípulas. Percebíamos que ela não queria fazer sucesso diante de nós, mas aquela "dança" transcendia as emoções e significava, para nós, que ela sentia um profundo prazer em "ser enfermeira", e conseguia transmitir seu prazer nos mínimos detalhes do preparo e da execução de um procedimento de enfermagem.

A impressão era a de que ela talvez jamais tenha se dado conta, ou pensado, que poderia ser, ela mesma, 0 ponto central de um ritual de intimidadef, no âmbito da arte interpretada à medida que ensinava a higiene corporal e o banho do cliente. Pensando na De Felice, vale enfatizar que nenhuma artee, portanto, nem a arte de enfermagem pode dispensar o ritua $/$, como a ciência não dispensa 0 ritual da pesquisa ou a religião não dispensa o ritual da liturgia. E como De Felice ensinava este ritual? Neste ponto, algumas questões são necessárias:

- Por que (re)lembrar ou pensar em De Felice, quando 0 foco central do estudo é o banho no leito?

- Será que esta técnica / tecnologia é relevante para a enfermeira e sua arte, ou estamos romantizando uma prática já aprendida há anos?

- 0 que esta técnica / tecnologia tem de importância para merecer esforço intelectual e justificar um estudo sobre ela?

- 0 que as enfermeiras pensam, de essencial, sobre 0 banho no leito?

Com base nessas questões, pensamos em (re)apresentar o banho no leito para a reflexão das enfermeiras e como ponto de partida para um estudo, 0 qual, no mínimo, serve para expor o compromisso que temos para com a Enfermagem, profissão que entendemos como prática científica e terapêutica. De um plano bem geral, a técnica pode ser executada através dos seguintes passos sintetizados (2):

\section{O Banho no Leito, um procedimento para cuidar e ensinar - método e/ou ritual}

\section{O Preparo inicial}

- Preparar todo o material necessário para o banho; - Preparar psicologicamente o paciente, isto é, explicar o que vai ser feito; 
- Preparar o ambiente;

- Cercar a cama com biombos e desocupar a mesa de cabeceira;

- Colocar a cadeira aos pés da cama;

- Trazer a comadre e apoiá-la sobre a cadeira (caso o paciente não tenha uma para uso individual);

- Trazer o material de banho e apoiá-lo sobre a mesa de cabeceira.

\section{A técnica}

- Soltar a roupa de cama, começando pelo lado oposto;

- Dobrar a colcha e colocá-la na cadeira;

- Posicionar a(o) cliente em posição ginecológica, e instalar a comadre protegida com peça de tecido, para evitar diferenças bruscas de temperatura entre o corpo e o metal / plástico;

- Passar a mesa de cabeceira para os pés da cama;

- Fazer a lavagem dos órgãos genitais externos e secá-los;

- Colocar o jarro da lavagem, as cubas rime redonda, separadas pelo saco de papel;

- Levar o material e a comadre para a sala de limpeza;

- Lavar a comadre, guardá-la na mesa de cabeceira, se for de uso individual (caso contrário, deixá-la em suporte da enfermaria);

- Retirar o lençol móvel e o impermeável pelo método indicado / aprendido e levar o impermeável para arejar;

- Providenciar a roupa limpa, deixando-a sobre a cadeira;

- Trazer o jarro com água, a bacia e a luva de banho (se não estiver na mesa de cabeceira);

- Retirar a camisa da(o) cliente e colocá-la no espaldar da cadeira;

- Posicionar a toalha de rosto sob a cabeça, forrando o travesseiro;

- Lavar, enxaguar e secar o rosto; dobrar a toalha de rosto, guardando-a no porta toalhas;

- Posicionar a toalha de banho sobre o peito, descer 0 lençol em leque até a região pubiana, deixar os braços sobre a toalha, lavar e enxugar primeiro o braço mais distante e, a seguir, o mais próximo;

- Lavar as duas mãos juntas imersas na água da bacia; se a(0) cliente não puder movimentar os braços, laválos separadamente e enxugá-los;

- Solicitar a(o) cliente para posicionar os braços sob o travesseiro, lavar e enxaguar o peito e as axilas - primeiro o lado mais distante e, depois, o mais próximo; um cuidado todo especial deve ser dado à base dos seios, se for mulher;

- Proteger o peito da(o) cliente com a toalha e lavar e enxaguar o abdome, primeiro o lado mais distante e, depois, o mais próximo; e, na seqüência, lavar enxaguar e secar os membros inferiores, primeiro o mais distante e depois o mais próximo; - Lavar os dois pés juntos imersos na água da bacia; se a(0) cliente não puder movimentar os pés ao mesmo tempo, lavá-los separadamente e enxugá-los;

- Após posicionar a(0) cliente em decúbito lateral direito, esquerdo ou ventral, lavar e enxaguar o dorso e nádegas, primeiro o lado mais distante e depois, 0 lado mais próximo enxugando-os em seguida;

- Trocar a roupa, refazer a cama e verificar se a(0) cliente está ou se sente confortável;

- Lavar o material / utensílios da técnica para limpálos e guardá-los.

Reposicionar o banho como técnica fundamental, pelo que concerne à idéia de completude, e complexidade, teve o propósito de (re)lembrar Elvira De Felice Souza como professora que nos ensinava a olhar as técnicas e procedimentos de enfermagem como "instrumentos ou meios específicos" mediante os quais a enfermagem consagrou-se como "arte de cuidar". Além disso, entendemos que o ritual do banho no leito é o componente específico de uma prática que tem como fluir um processo/ produto de essência social, e que é obtido pela transformação de fatos do domínio social. $\mathrm{Na}$ antropologia, os rituais fazem parte das práticas e dos costumes de um povo, de um grupo social, e cujo ponto de origem histórica se encontra nas práticas religiosas.

Assim, nos rituais, quando olhamos para o ser humano, devemos olhar para ele com suas diferenças, tais como condicionadas pelo ambiente, sexo, idade, educação e outros aspectos. Na ritualística da Enfermagem, 0 banho no leito obedece, ainda, a um método com propósito e passos prédeterminados segundo uma intencionalidade objetiva, exigindo dos profissionais todo um preparo de base científica, tecnológica e ambiental.

$\mathrm{Na}$ tentativa de responder a perguntas apresentadas, traçamos alguns objetivos a serem alcançados ao final do estudo:

- Descrever como as enfermeiras manifestam e fruem a experiência de banhar e ser banhada;

- Caracterizar os significados atribuídos pelas enfermeiras ao banho no leito. ${ }^{f}$ 


\section{DESENVOLVIMENTO DA PESQUISA}

Decidimo-nos por um estudo exploratório, de natureza descritiva (quanti-qualitativa), porém, eminentemente acadêmico como oportunidade para colher informações compatíveis com "manifestações das enfermeiras" sobre banho no leito, quando esta técnica foi executada em um Laboratório de Fundamentos de Enfermagem "por elas(es) e com elas(es)" - as enfermeiras ("sujeitos objetivados", na pesquisa, aceitaram participar do estudo, obedecendo a princípios de livre consentimento e disposições em atitude e comportamentos éticos). Todos os envolvidos, na pesquisa assumiram o pressuposto de que as manifestações (gestos e falas) corresponderiam a "significados da técnica de banho no leito para as enfermeiras" (dados / informações obtidos).

Todavia, a abordagem metodológica foi sendo construída artesanalmente ${ }^{3}$, e ajustada à medida em que a cena do banho ia acontecendo. Na ocasião, as 32 enfermeiras / alunas de pós-graduação (mestrado) foram subdivididas em quatro grupos de 08 participantes cada um, para desenvolver atribuições e registrar "gestos e falas", como se segue: o primeiro grupo observava quem banhava, o segundo observava quem observava, 0 terceiro observava quem estava sendo banhada e 0 quar to grupo destacava os princípios científicos aplicados.

$E$, então, denominamos esse momento (coleta de dados) de encenação de reflexão ${ }^{7}$ - um espaço para "reflexão sobre 0 ato de banhar", onde as participantes observavam os corpos e comportamentos durante as atividades; momento em que se manifestaram ou denunciaram gestos ou falas sobre a técnica executada; momento apropriado à construção de novo ou outro conhecimento sobre banho no leito; e, também, o local em que as cenas foram produzidas para serem objeto de reflexão, após o banho no leito. Os "sujeitos - objetos" do estudo foram identificados conforme o quadro abaixo.

\section{Q uadro I:}

Distribuição das participantes por áreas de atuação. Rio de Janeiro, 2004

\begin{tabular}{|l|c|}
\hline \multicolumn{1}{|c|}{ Especificações } & Total \\
\hline Enfermeiras assistenciais & 14 \\
Enfermeiras assistenciais e docentes & 11 \\
Enfermeiras docentes & 07 \\
Total & 32 \\
\hline
\end{tabular}

Vale esclarecer que das participantes, 25 enfermeiras trabalhavam em hospital geral da rede pública e tinham experiência com clientes de alto risco (CTI de adultos e crianças). Seu tempo médio de experiência profissional variava de três a 15 anos e sua faixa etária estendia-se de 26 a 40 anos. Todas eram do sexo feminino.

Após a encenação de reflexão, discutíamos a experiência para registrar as falas de todas as participantes, o que era registrado/anotado pelas docentes. Os dados produzidos resultaram do material entregue pelas alunas (sujeitos objetivados), com informações e questionamentos sobre seus sentimentos, dificuldades, comportamentos, e reações face ao banho executado.

Nas informações colhidas, destacamos as expressões sobre o banho no leito, que correspondem ao que consta dos dois primeiros objetivos. Então, assim, foi possível identificar dois grandes "núcleos", a saber:

- Banho no Leito - uma Tecnologia do e para 0 Corpo que Toca e Fala;

- Banho no Leito - uma Tecnologia do e para 0 Corpo que Toca e Cala.

Esses dois "núcleos" foram devidamente analisados e discutidos com base no apoio teórico adotado, e são apresentados a seguir.

Dados do primeiro núcleo:

\section{BANHO NO LEITO - UMA TECNOLOGIA DO E PARA "O CORPO QUE TOCA E FALA"}

(...) sentimos muitas dificuldades, quando estamos banhando um corpo que está nu, que não conhecemos; é uma invasão da intimidade dele e da minha;

(...) sempre me sinto invadindo um espaço que não é meu; o banho talvez seja o contato mais prolongado que um profissional tem com o outro, acho que é só na enfermagem que isto acontece;

(...) no banho toco e pego no cliente em todo o seu corpo, sem pedir licença [!?]; é um procedimento manual e rotineiro, que exige contato com as mãos; é um "mexe-mexe" contínuo, é um passa sabão, lava, seca, faz massagens, é muito toque;

(...) ali, no altar [!?] conversamos com o cliente, às vezes falamos, às vezes só olhamos;

(...) é preciso treinar muito para adquirir habilidade de fazer a técnica com segurança;

(...) o banho proporciona higiene e deve ser rotina no plano de cuidados;

(...) eu sei fazer um banho bem feito, faço massagens de conforto, e com tapotagem depois dele; 
(...) é uma tarefa cansativa e a gente gasta muita energia: vira o corpo para lá, vira para cá; limpa, lava, passa sabão, passa creme; é uma ação de enfermagem que só sabe quem realmente faz 0 banho; banhar e pegar, segurar para limpar, sentir cheiro, deixar o corpo cheiroso;

(...) me sinto muito cansada depois desta atividade e sempre acho que meu corpo também precisa de um banho, pois acho que conforta e relaxa ;

(...) é preciso saber fazer um banho para que ele seja diferente de qualquer outro; o banho faz parte de minhas tarefas diárias; e eu nunca prestei atenção se aquele corpo era de homem ou de mulher.

Dados do Segundo Núcleo:

BANHO NO LEITO - UMA TECNOLOGIA DO E PARA "O CORPO QUE TOCA E CALA"

(...) Foi um momento de muito silêncio, ninguém sequer suspirava; os risos desconcertados justificam o nervosismo, que tomou conta de todos no laboratório;

(...) todos baixaram os olhos por respeito ou por vergonha, pela exposição do corpo nu; suspiro para equilibrar o próprio corpo que estava contraído, tenso, duro;

(...) insegurança nos movimentos para tocar o corpo;

(...) é difícil sentir odor desagradável e não expressar o desconforto;

(...) fico tão tensa que esqueço; expressão de prazer ao olhar o corpo confortado;

(...) expressão de alegria e relaxamento; expressão de tranqüilidade que até esqueço, às vezes, os passos da técnica;

(...) rostos contraídos e toques rápidos, agitados; não sei o que sinto quando banho, acho que só cansaço.

Vale destacar que, em vários momentos, as participantes mencionavam a De Felice que era lembrada, principalmente se os passos da técnica e os momentos do ritual não eram seguidos como na ordem requerida, ou quando o corpo da aluna que se desempenhava como cliente ficava exposto.

\section{ENCONTRANDO GESTOS NO CORPO QUE FALA E NO CORPO QUE CALA DIANTE DO BANHO EXECUTADO}

Independentemente de se o corpo fala ou cala, nos dois núcleos aparecem as informações concretas, racionais, objetivas das enfermeiras diante do banho no leito. São expressões verbalizadas de "sentimentos objetivados", ou para dizer melhor, são expressões sobre uma "ação de cuidar" que não se realiza, na esfera do agir profissional, se a enfermeira não tocar o corpo da(o) cliente. 0 toque torna-se inter-médio, ou intermediador, entre duas ou mais pessoas que se encontram no espaço de cuidar, mesmo que não seja reconhecido como elemento indispensável ao instrumental da técnica.

Assim, o toque no banho torna-se o início do movimento que acontece no ato de banhar. Serve para a troca de energia, de emoções, de ações entre a pessoa que realiza a técnica de "banhar" e a que é "banhada". É (talvez) a "interação mais profunda", como afirmou uma das enfermeiras, tornando-se em algo mais do que um simples detalhe para efetivar a higiene corporal. 0 toque, no banho no leito (que é cuidado direto), transcende à própria técnica de banhar clientes, e se firma, a nosso ver, como a base primordial de uma ação terapêutica de enfermagem.

Sabemos que as interpretações para analisar e discutir os resultados, de certa forma estão carregadas de nossas influências pessoais. Mas, como sem interpretação não há sentido ${ }^{4}$, cabe-nos destacar, portanto, que o banho no leito abrange tanto dificuldades para "quem dá o banho" como para "quem é banhado", e ousamos relevar os conteúdos das falas, ou realçar os enfoques dados pelas enfermeiras que se expressaram, de modo mais freqüente, sobre o banho no leito conforme mostrado no quadro a seguir.

\section{Quadro II:}

Freqüência de temas/enfoques encontrados nas falas das enfermeiras. Rio de Janeiro, 2004.

\begin{tabular}{|l|l|}
\hline \multicolumn{1}{|c|}{ Especificaçõ es: } & $f *$ \\
\hline É manual e rotineiro; & 29 \\
É invasão de intimidade; & 26 \\
É tocar, é pegar no cliente o tempo todo e em todo o corpo; & 21 \\
É proporcionar higiene; & 19 \\
É ficar diante do corpo nu; & 18 \\
É gasto de muita energia; & 18 \\
É um mexe-mexe contínuo; & 17 \\
É treinar muito para adquirir habilidades; & 16 \\
É uma ação de enfermagem que só sente quem trabalha; & 13 \\
É contato mais prolongado; & 12 \\
É massagem e muito toque; & 09 \\
É sentir cheiro; & 08 \\
É não pedir licença para tocar; & 06 \\
É não perceber o sexo de quem está sendo banhado; & 06 \\
É massagem de conforto; & 03 \\
É sentir necessidade de tomar banho; & 03 \\
\hline
\end{tabular}


Em suas falas, as enfermeiras referem o banho como uma atividade complexa e que exige, além dos princípios de enfermagem - de limpeza, higiene corporal e requisitos da ambiência, outros conhecimentos de ciências básicas. 0 simples fato de tocar torna-se indício para o estabelecimento de uma política ${ }^{(5)}$ de relacionamento humano. Mas elas falam de uma técnica fundamental de enfermagem, e falam da mesma como ocasião de perda de energia, de conversa, de sentir odores e de necessidade pessoal de tomar banho.

0 "toque" está em todas as informações obtidas, e por justa razão, pois faz parte de todos os movimentos políticos, afetivos, culturais, humanos. 0 toque é elemento da maior integração humana possível e a pele é a primeira barreira interposta, ou a interferir, entre os contatos de um com o outro e destes com o mundo ${ }^{6}$.

Deste modo, o banho no leito deixa de ser simples tarefa manual para ser uma tecnologia que abrange 0 corpo inteiro de dentro para fora e de fora para dentro. 0 toque expressado em gesto e emoção estimula terminações nervosas da pele, desencadeando sensações prazerosas ou de desconforto, sendo ele denominado toque sensivel. Assim, tocar é mais do que um simples contato, é ficar atento, é tomar consciência sobre o próprio toque ${ }^{7}$. Tocar é sentir, é coisa de "mão e pele". Mas a pergunta é: se é só de mão e pele, onde fica "quem toca nosso corpo"? Se 0 toque atingisse somente a pele, a sensibilidade seria simplesmente externa. Mas as sensações do toque são mais profundas, pois correspondem a cargas e descargas internas. Além disso, a água do banho estimula as terminações nervosas e, com o toque e as massagens, os estímulos aumentam e desencadeiam diversas sensações.

Dessa forma, sendo o banho mais do que simples limpeza torna-se, com efeito, higiene corporal, e é quando a técnica se transforma em tecnologia - uma tecnologia das mãos. No banho no leito, sucede um conjunto de processos e a técnica, em si, é peculiar, específica, de uma prática científica e de um saber profissional da Enfermagem - uma ciência em construção.

0 banho é visto pela enfermeira como uma ação que confere com um tipo de conhecimento próprio de uma profissão institucionalizada e regulada por lei; e há muita bagagem intelectual por detrás desse procedimento $\mathrm{e}$ desse tipo de conhecimento. No banho no leito, os movimentos da mão de quem cuida no corpo de quem é cuidado proporcionam mudanças físicas e emocionais em relação à pele, aos músculos, ao sistema nervoso, à química corporal, à dispersão de fadiga e às trocas de energias.

Entretanto, no plano da arte de cuidar, é imperativo reconhecer que a tecnologia de enfermagem não é a "tecnologia das máquinas", é a tecnologia das mãos, correspondendo ao sentido da idéia de o corpo da enfermeira como instrumento do cuidado (8: 154).

\section{O BANHONO LEITO- TECNOLOGADO E PARA O CORPO QUE TOCAE CALA}

Este núcleo completa os pensamentos das enfermeiras, principalmente no que concerne aos "gestos silenciosos", sem palavras, para expressar emoções e sentimentos do sujeito profissional, que envolve seus toques e seu corpo, em todo o procedimento do "banho no leito". É neste núcleo que se encontra a linguagem não verbal do corpo - o corpo que toca e cala. Trata-se de manifestações de quando o corpo fala através de gestos e posturas ${ }^{9}$.

Contudo, as enfermeiras, nas mais das vezes, não se dão conta dessa linguagem. Tampouco a De Felice nos falava sobre ela. De certa forma, nós éramos orientadas a controlar nossos corpos, com uniformes um tanto longos, folgados, e não nos era permitido o uso de maquiagem e de adereços. Nenhuma censura, aqui, à De Felice (e nem às suas assistentes). Afinal, era uma exigência da Escola e como está disposto no sistema Nightingale, as enfermeiras deveriam saber andar, e a suavidade no movimento do corpo era recomendada para evitar constrangimentos e ruídos, espécie de barulho típico do farfalhar das roupas ou do toque pesado do pé no chão ${ }^{10}$.

Assim sendo, diante do banho no leito, tal como executado, as enfermeiras expressaram-se em termos de gestos e sentimentos, como apresentado no quadro a seguir.

\section{Q uadro III: \\ Freqüência de gestos e sentimentos nos registros das enfermeiras. Rio de Janeiro, 2004.}

\begin{tabular}{|l|l|}
\hline \multicolumn{1}{|c|}{ Especificações: } & $f *$ \\
\hline Foi um momento de muito silêncio & 28 \\
Relaxamento e tranqüilidade durante o banho & 21 \\
Todas baixaram os olhos de vergonha e respeito pelo corpo nu & 16 \\
Prazer em ver o corpo confortado & 14 \\
Emoção diante de possibilidade de poder confortar & 12 \\
Ninguém sequer respirava & 11 \\
A tensão fez esquecer os passos da técnica & 11 \\
Risos desconcertados justificavam o nervosismo & $?$ \\
Suspiro e corpo contraído & 08 \\
Corpo duro e tenso & 05 \\
Difíil sentir odores & 04 \\
Insegurança nos movimentos de tocar & 03 \\
\hline
\end{tabular}

* Número de vezes que o tema (fala) apareceu no discurso das enfermeiras. 
A subjetividade permeia todo este núcleo através de expressões corporais associadas, ou integradas, ao mundo do trabalho das enfermeiras. Em outras palavras, é a própria expressividade profissional que abarca 0 modo como as enfermeiras percebem ou vêem 0 banho no leito, uma técnica que envolve atitude e comportamentos, e que adquire um outro sentido, às vezes, como que criando outros "dispositivos de valor" para o cuidado de enfermagem. Vale dizer que a subjetividade individual encontra-se em ambiente de território existencial, ou seja:

Um território do objeto de pensamento, e que exige a criatividade das pessoas que aí se encontram. Os dispositivos de valor são criados a partir de novas maneiras de abordar a subjetividade (e o real objetivado) - maneiras designadas de creacionista, auto-poética, auto-fundadora - é repensar [a totalidade] partir do que existe ${ }^{12}$.

Quando resolvemos (re)lembrar a De Felice, acreditávamos que não seria possível falar de banho no leito sem considerá-la como a grande mestra que, à sua maneira, passou-nos o estímulo para a arte e para 0 conhecimento científico. Ao longo da experiência profissional, o banho no leito vem perdendo sua peculiaridade tornando-se, na compreensão delas(es), uma tarefa de caráter simplesmente "manual". Lembrando De Felice, para cada ação de enfermagem, ela dizia: antes de tudo, deve-se fazer o preparo psicológico da pessoa a ser cuidada?

Tal como pensamos, o preparo psicológico, além do cliente, envolve as próprias enfermeiras e deve ser entendido, por isso mesmo, como cômputo de requisitos bio-psico-sócio-eco-antropológicos, porquanto leva em conta a idéia e a expressão das pessoas entendidas como seres desejantes, expectantes, politicos, históricos, sociais, espirituais e culturais. E tudo isto ainda é, para nós, um estilo próprio de cuidar - o cuidar na enfermagem.

As enfermeiras, no estudo, "não-dizem". Mas, quando observadas, expressam gestos que traduzem ou denunciam comportamentos reservados, escondidos. Para elas, o banho no leito é como se fosse "uma invasão de intimidade". Mas, mesmo assim, na execução desse procedimento, elas agem em silêncio. Silêncio considerado, por nós, como o "não dito", e que encontra sustentação no imaginário, pois o não dito vem do imaginário do sujeito, de tal maneira que ele sabe o que 0 imaginário do outro sabe, mas que a lei do outro não pode aceitar abertamente ${ }^{13}$.

Este núcleo mostra toda a dimensão subjetiva de nossa prática, e na qual o corpo continua sendo controlado por todos. Os gestos vistos e registrados realizados pelas enfermeiras indicam "bem e malestar" como indícios tangíveis à uma semiologia da expressão e que pode ser tanto de ordem física como emocional.

Dizer que as enfermeiras não falam, não verbalizam claramente, mas expressam a própria subjetividade nos procedimentos que executam, nos cuidados que prestam, na ajuda que oferecem, equivale a dizer que a expressão da subjetividade pode (talvez) corresponder a enunciados/afirmativas de que tanto precisamos e que valem para o "não-dito".

Emoção, sensibilidade, subjetividade podem significar, nas mais da vezes, "vazios de conhecimento", que conferem com enunciados que representam, simbolicamente, um "espaço desconhecido" ou como se fossem "buracos negros", dos quais não se consegue falar. Dizer o que pensamos, sem ocorrer riscos de malentendimentos e expor nossas idéias é o melhor a fazer do que calar, ou ficarmos "omissas" diante dos próprios achados ou informações que temos. Razão porque, mesmo correndo risco de redundância, cumpre-nos afirmar que o banho no leito é a técnica mais básica da arte de enfermagem, pois, além de tudo, é integradora de conhecimentos, de interações e de inter-relações.

Contudo, não se pode ensinar e aprender a técnica do banho no leito sem adentrar nos meandros do fundamento lógico, racional, imprescindível às explicações concernentes à própria concepção de corpo, entendido como depositário de emoção, desejo e sensibilidade. A sensualidade e a sexualidade inexistiam no discurso da Enfermagem como categorias a serem consideradas, objetivamente, no cuidado de enfermagem à época em que De Felice ensinava-nos a cuidar. Tais categorias somente foram incorporadas no discurso da Enfermagem há bem pouco tempo e, ainda assim, as enfermeiras neste estudo baixam os olhos, calam e se dizem desconfortadas diante do corpo nu. E note-se que este núcleo mostra, também, os movimentos físicos/sensoriais - respostas do corpo (do cliente e da enfermeira) a tudo que os sentidos captam na natureza.

Falar de corpo e do tocar é falar dos sentidos, estes órgãos que situam o ser humano em seu próprio mundo e em contato com as pessoas que o cercam e que o tocam. Em qualquer fato ou fenômeno que acontece, o corpo percebe, como se fosse o depositário de um radar que tudo capta. As enfermeiras, quando estão banhando seus clientes, podem olhar e não ver, tendo-se em conta afirmações como nunca percebi o sexo do meu cliente, nunca parei para olhar se o corpo era de homem ou de mulher. 
Há que se pensar no fato de estarmos diante do corpo que cuidamos, e que não se trata do ouvido que ouve, da boca que fala, do nariz que sente odor ou da mão que toca. Por detrás desse fato há muito mais em causa: - há emoções e sentimentos, há paixão e amor; e pode haver também ódio, repulsa e irritação. Afinal, os sentidos são pequenos transmissores corporais e definem os limites da consciência ${ }^{14}$.

Contudo, pelos dados obtidos, parece que as enfermeiras não estão ligadas à questão dos sentidos. A nosso ver, uma técnica como o banho no leito envolve mais do que percepção e sensibilidade, envolve compromisso, cometimento, e não apenas a maneira pessoal de utilizar-se os sentidos como partes do aparato biológico do corpo.

\section{OS SENTIDOS - A ENCENAÇÃO DO CORPO DURANTE $O$ BANHO NO LEITO NO PRESENTE: E AGORA ONDE ESTÁ DE FELICE?}

Os dois núcleos identificados, neste estudo, caracterizam uma questão polêmica da ação de enfermagem (aspecto epistemológico?), aqui designada como a questão do "corpo que banha e do corpo que é banhado", e da qual resultam "manifestações" conotando, talvez, significados de "fronteiras perigosas", que não ousamos atravessar, ainda, sem medo, seja para compreender ou para explicar. Sem dúvida, precisamos de mais pesquisas que falem por evidências.

Ora, a De Felice nos orientava sobre o toque, e nos ensinava que o mesmo não deveria ser tão forte para criar estímulos de desprazer e desconforto, e nem tão suave para criar estímulos de prazer e confor to. Pensamos que ela não aprofundou a questão corporal, mas ela parecia saber, exatamente, 0 que estava dizendo e, também, 0 que podia condizer com nossa compreensão. Sua preocupação maior era com o aspecto "sagrado" da profissão e, por suposto, para ela qualquer aspecto "profano" não podia fazer parte de representações que interessam ao sentido da Enfermagem e à posição profissional de seus exercentes. Mas ela indicava pistas para encontrarmos o real objetivo entre o que seja "for te ou suave", na medida certa de tocar o corpo do outro.

Entretanto, na questão de tocar o corpo do outro, nada é tão fácil de se fazer, ou de aprender e ensinar. No que concerne à tecnologia e aos procedimentos da enfermagem, o banho no leito é uma terapêutica do conforto $^{9}$ - nos aspectos físico e emocional. 0 aspecto do confor to ${ }^{h}$ é fundamental para a prática de cuidar na enfermagem - tanto serve aos cuidados de higiene corporal como, também, a medidas de dar alívio, encorajamento, consolo, equilíbrio emocional, e não apenas aos meios de assegurar necessidades básicas e fisiológicas ${ }^{15}$. As falas, aqui apresentadas, traduzem as respostas das enfermeiras participantes e servem para identificar as emoções, verbalizadas ou não.

Quando apreciamos o máximo de freqüência, podemos compreender as implicações para 0 significado real do procedimento de enfermagem, tal como sucedido na encenação exploratória do banho no leito. Assim, os gestos ou falas que perpassam e transcendem a estrutura do cuidado de enfermagem correspondem a significados inerentes aos atos de banhar e ser banhada, e podem mais que o simples toque causar benefício ou prejuízo, e merecem sérias reflexões acerca de como melhor compreender e explicar um procedimento a ser efetuado. No plano da Enfermagem, entendida nos termos da estética e da prática substantiva, muito mais se poderia realizar para preencher vazios de conhecimentos, alguns bem fundamentais.

No mais, vale dizer que os corpos que dão o banho e os corpos que são banhados, como na experiência deste estudo, não são seres metafísicos ou arquitetados artificialmente. São corpos humanos e, de fato, corpos sensiveis. Eles se tornam sensíveis à medida em que ampliam a experiência de viver, posto que o sensível é fonte de riqueza espiritual, de fortaleza corporal e permite a plenitude do coração ${ }^{16}$.

Então, cabe-nos acrescentar que todos os "sentidos" estão presentes na harmonia sinergística que intermedia a aproximação dos corpos, o que é capaz de engendrar uma erótica coletiva, um eros de múltiplas faces, ou uma espécie de aura a envolver os ambientes em que se banha a própria enfermeira, numa ritualística do cotidiano do trabalho e de sua prática profissional. 


\section{Referências}

1. Taylor FW. The Principles of Scientific Management. New York: Harper, 1947.

2. Parsons E. Modern Nursing in Brazil. The American Journal of Nursing, 26(6): 1927.

3. De Felice e Souza E. Novo Manual de Enfermagem. Rio de Janeiro: Bruno Buccini Editor.

4. Becker HS. Métodos de Pesquisa em Ciências Sociais (Tradução de Marcos Estevão e Renato Aguiar). São Paulo: HUCITEC, 1999.

5. Orlandi EP. Interpretação, autoria, leitura e efeitos do trabalho simbólico. Rio de Janeiro: Vozes, 1995.

6. Sennett R. Carne e Pedra: - o corpo e a cidade na civilização ocidental. Rio de Janeiro: Record, 1997.

7. Montagu A. 0 Toque: - dimensão humana da pele. 3ạ ed. São Paulo: Summus, 1988.

8. Levy RB. Só posso tocar você agora. 10å ed. São Paulo: Brasiliense,1993.

9. Figueiredo NMA; Carvalho V. O Corpo da Enfermeira como Instrumento do Cuidado. Rio de Janeiro: Revinter, 1999.

10. Weil P.; Tompakow R. 0 corpo fala: - A linguagem silenciosa da comunicação não verbal (20ミed.). Petrópolis RJ: Vozes, 1986.

11. Nightingale F. Notas sobre Enfermagem (Tradução de Amália Corrêa de Carvalho). São Paulo: Cortez / ABEn / CEPEn, 1989.

12. Guattari F. Entrevista. Cadernos de Subjetividade / Núcleo de Estudos e Pesquisas sobre Subjetividade, 1-2(1-2): 1-36, 1996 (2. aed.).

13. Olivenstein C. 0 não-dito das emoç̧ões. Rio de Janeiro: Zahar, 1989.

14. Ackerman M. Uma história natural dos sentidos. Rio de Janeiro: Berthrand do Brasil, 1992.

15. Mussi FC. Conforto. Revista da Escola de Enfermagem da USP, 30(2): 1996.

16. Maffesoli M. No Fundo das Aparências. Rio de Janeiro: Vozes, 1996.

\section{Notas}

a Elvira De Felice Souza, Enfermeira Graduada da Escola de Enfermagem Anna Nery. Doutor / Docente Livre, Professora Titular do Departamento de Enfermagem Fundamental, onde exerceu por cerca de 50 anos, suas atividades de magistério. Professor Emérito UFR). Aposentada, continua colaborando com a Escola (PósGraduação stricto sensu e Congregação), participando de atividades comemorativas e outras. Escreveu três livros: Administração de Medicamentos e Preparo de Soluções, Enfermagem Básica e Manual de Técnica de Enfermagem - este último é o mais divulgado no Brasil.

\begin{abstract}
${ }^{b}$ Ambiente do Cliente - 0 ambiente do cliente deve ser preparado de modo a oferecer conforto e segurança - cama, cadeira e mesinha - armário, escadinha, biombo e roupa de cama; o preparo do mesmo obedecia a requisitos nightingaleanos, com instruções para mante-10 bem arejado, limpo, iluminado e com ausência de ruídos desagradáveis, para que a natureza (do corpo do enfermo) exercesse sua ação de auto-reparação ou cura; princípios de enfermagem asseguravam que a enfermeira proporciona essas condições. Para as autoras deste estudo, 0 ambiente envolve assistentes e assistidos e, assim, a natureza humana com fundamentos biológicos da cultura e da vida dos homens e mulheres; e envolve ainda os espaços em que habitamos e onde trabalhamos, que conferem com a terra simbólica e real - é o espaço de uma espécie de Ecologia de Enfermagem, que proporciona aos clientes bem-estar físico e emocional, um estado de ser e estar que se manifesta como forma de "organicidade de evolução cósmica" (visão universal telúrica)??:p.??.
\end{abstract}

'Tarefa - Atividade que se deve concluir em prazo certo, como nos termos de empreitada, nas jornadas de trabalho nas fábricas; é regulada por objetivos traçados segundo os princípios tayloristas e são estabelecidos para aumentar a produtividade - nas fábricas, os trabalhadores eram pagos por tarefas executadas.

${ }^{d}$ Banho no Leito - Ação e atividades técnicas com que, na enfermagem, a enfermeira exerce, primordialmente, sua arte de cuidar, a qual, no ritual do cotidiano assistencial, corresponde a cuidados específicos realizados por corpos para cuidar de corpos.

e Complexidade - Grau de dificuldade compatível não apenas com quantidade de unidades e de certas interações a desafiarem nossas possibilidades, mas compreende também incertezas, indeterminaçōes, fenômenos aleatórios; requer cálculo e entendimento, e está inscrita/ manifesta nos fenômenos; a complexidade abrange a incerteza que rege os sistemas ricamente organizados; está ligada a uma certa mistura de ordem e desordem estatística, reinando ao nível das grandezas, sendo a ordem (pura e estática), e a desordem (desequilibrio ou estado indeterminado) é a das unidades elementares. Pensar em complexidade é poder trabalhar com o insuficiente e 0 vago e aceitar a ambigüidade certa (na relação sujeito/objeto, ordem/desordem, auto-hetero organização), o que exige o reconhecimento de fenômenos, como liberdade e criatividade inexplicáveis fora do quadro complexo, 0 único que permite a sua aparição.

${ }^{\dagger}$ Ritual de Intimidade - Em nosso entendimento, ele compreende atividades executadas por pessoas íntimas, convivendo no mesmo ambiente e que podem ou aceitam expor seus corpos - um ao outro, sem vexame, constrangimento ou vergonha. É um ritual familiar, 
particular, no qual ninguém pode entrar se não for convidado, se não for aceito. Com os desvios da saúde e a internação de enfermos, este ritual transfere-se para o hospital e os parceiros afetivos (familiares ou companheiros) são substituídos, sem opção ou escolha, por enfermeiras(os).

${ }^{g}$ Ritual - Componente especifico de uma prática que tem como fluir um processo/produtor de uma essência social que é obtido, pela transformação de fatos do domínio social (SMITH). Para os antropólogos os Rituais fazem parte das práticas e dos costumes de um povo, de um grupo social, cuja origem se encontra nas práticas religiosas. Nos rituais quando olhamos para o ser humano, devemos olhar para ele com suas diferenças, condicionadas pelo ambiente, pelo sexo, pela idade, pela educação (Rabuske)

Smith, Robertson W - The religion of the semiles: the fundamental instituicions, New York, 1972

Rabuske, Edwin A - Antropologia Filosófica. Ed. Vozes, Petrópolis, 1993

${ }^{n}$ Conforto - Mussi (1996) faz uma revisão de literatura sobre confor to, na qual destaca que a Enfermagem vem considerando-o como importante e fundamental para a prática profissional citando mais de 15 autores. Dentre os vários conceitos, nós destacamos alguns para um melhor esclarecimento do que queremos dizer como terapêutica do conforto: estado de alívio, encorajamento ou consolo, no qual as necessidades fisiológicas básicas de sobrevivência são satisfeitas e a homeostase fisiológica é mantida. Nós acrescentamos as expressões homeostase emocional, estado de comodidade e bem-estar em que a pessoa está à vontade consigo mesma e/ou com seu ambiente. $\mathrm{E} 0$ estado de relaxamento, quando as pessoas experimentam emoções positivas livres de extrema tensão e de dor. E o estado de harmonia, resultado da integração.

\section{Sobre as Autoras}

Nébia Maria Almeida de Figueiredo

Doutora em Enfermagem - Escola de Enfermagem Anna Nery ( UFR). Professora Titular do Departamento de Enfermagem Fundamental - Escola de Enfermagem Alfredo Pinto / UNIRIO. Pesquisadora do CNPq.

\section{Vilma de Carvalho}

Doutora / Docente-Livre e Professora Titular do Departamento de Enfermagem de Saúde Pública - Escola de Enfermagem Anna Nery / UFRJ. Professora Emérita da UFR). Pesquisadora do CNPq.

\section{Maria Antonieta Rubio Tyrrell}

Doutora em Enfermagem e Professora Titular - Departamento de Enfermagem Materno Infantil da Escola de Enfermagem Anna Nery / UFRJ. Pesquisadora do CNPq. 